\title{
The discovery, elucidation, philosophical testing and formal proof of various exceptions to medical sayings and rules
}

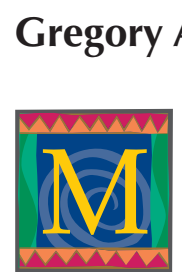

sum up a case by quoting one of the giants of medicine. ${ }^{1}$ Many of these sayings are so ingrained that they have become almost irrefutable truths, and even the most novice presenter may add an air of vast experience to his or her talk by finishing with one. When used in debating a medical case, a quotation is the ultimate disabling force that ends all further discussion, with the lucky quoter grudgingly declared the winner. When printed on the first page of a textbook, the quotation guarantees textbook relevancy for at least a generation. ${ }^{2}$ A cleverly quoted famous medical rule can hide a vast crater of missing knowledge when a resident is being questioned by a senior physician. To question these quotations is to disagree with Osler, mock Hippocrates and dismiss Galen. However, none of these sayings and rules has been subjected to an evidence-based review. I explored several famous sayings to discover whether they held errors, omissions or loopholes. As the saying goes, "fools rush in and out where the wise fear to jump up and down," or something like that.

An Internet search was conducted using search phrases such as "medical quote," "famous physician sayings," "medical rule of thumb" and "famous reflections upon the art of colonoscopy." A quotation was selected for study if I had ever heard it spoken by a staff physician when I was a medical student or resident or if I could imagine some pompous bigmouth quoting it when trying to get in the last word at grand rounds. Once a quotation or rule was selected for examination, I thought really, really, really hard about it to see if I could come up with some sort of contrary statement or exception to the rule. Philosophical testing was then performed according to the accepted procedure of Kline, ${ }^{3}$ whereby I tried to think of some clinical case I had seen where my exception to that rule would have been shown to be correct. If I couldn't think of a case, one was imagined to have occurred. If a real or fabricated case proving my point could be shown to exist or potentially exist, the exception to the rule was then considered proved. Once the new exception to the rule was documented to be a truth, a name was assigned to it containing the word "Kline." As a final test of truth, the exceptions to the rules were tried out

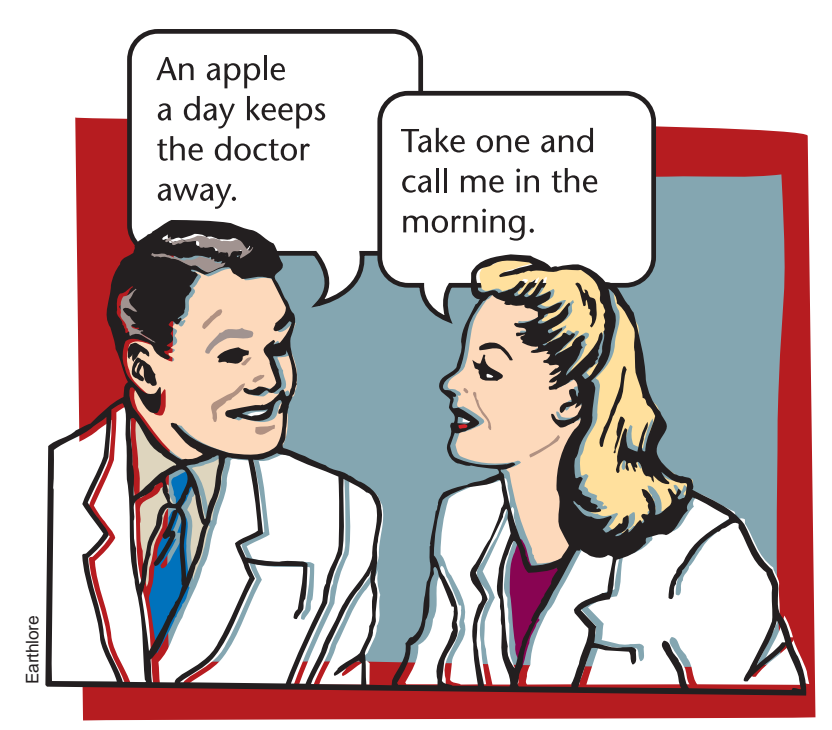

on colleagues to confirm universal agreement; however, if they suggested an exception that was wittier than mine, their suggestion was dismissed out of hand since it could no longer be properly assigned a name containing "Kline," which would constitute a study protocol violation.

The following sayings, quotations and rules have been determined to contain loopholes or exceptions. Where applicable, Kline's secondary laws are shown beside the original statements.

Anonymous Surgical Dictum: "When in doubt, cut it out" Kline's Surgical Dictation: "It's no sin to leave it in and think ag'in"

Wisdom of Voltaire: "The art of medicine consists of amusing the patient while nature cures the disease"

Kline's Contraire: "Nature kills the patient whose physician is more amused by philosophy and math than by medicine"

Occam's Razor: "Multiple symptoms and signs should be explained by a unified diagnosis"

Kline's Closer Shave: "Occam missed stuff"

Anonymous Internal Medicine Dogma: "When you hear hoofbeats, think horses, not zebras"

Kline's Dogma Collar: "If you don't know what a zebra looks like, good luck putting a saddle on that 'horse' " 
Bagliavi's Cornerstone: "The foundations of medicine are reason and observation"

Kline's Critical Keystone: "Reason and observation get much sharper when prodded by an unexpectedly abnormal lab test from the battery of random tests ordered."

Anonymous Italian Proverb: "Bene caca et declina medicos" [have good bowel movements and avoid doctors]

Kline's Italian Clarification: "Bene caca et declina describa al medico" [have a good bowel movement but avoid going on and on about it in the doctor's office]

Osler's Diagnostic Principle: "One finger in the throat and one in the rectum makes a good diagnostician"

Kline's Clean Finger Corollary: "If at all possible, become an endocrinologist"

Findlay's Boast: "The surgeon is a man of action who lives in an exhilarating world of knives, blood and groans. $\mathrm{He}$ may, in a relaxed moment, admit that the medical man is occasionally able to assist uncomfortable dowagers in the selection of a cathartic"

Kline's Roast: "A few more cathartics for the surgeons would decrease the amount of groaning in their exhilarating world and improve life for the rest of us"

Paracelsus' High Road: "The art of medicine cannot be inherited, nor can it be copied from books"

Kline's Download: “... yet it is readily practised by any who own computer and mouse"

Sacks' Secret: "There is only one cardinal rule: one must always listen to the patient"

Kline's Darker Secret: “... and then get the real history from the spouse"

Lydston's Certification Test: "No man is competent to pass an instrument upon a patient until he has practised the manoeuvre upon himself a few times"

Kline's Certification Jest: "It is a terrible thing to fail Lydston's gastroenterology qualifying examination"

Hippocrates' Posit: "The physician must be experienced in many things, but most assuredly in rubbing."

Kline's Opposite: "Once again, if at all possible, become an endocrinologist"
These results show that there are exceptions to every rule in medicine, or at least to every rule that I don't like. These exceptions are formally proven to be truth in this study, so all future letters to the editor disputing Kline's Rules can thus be preassigned to a category of non-truth. Such rule exceptions should be memorized (especially by their formal name) for use in clinical practice to help the physician avoid relying upon a famous rule that may lead to a time-honoured mistake.

The naming of each exception with a handle including the word "Kline" may help clinicians to remember each new rule. One colleague-reviewer suggested that this study be renamed "A brazen and blatant attempt to get one person's name permanently etched into medical immortality." After much consideration this title was rejected, but I ask, "who wouldn't want to someday see his or her name inscribed on a perfumed, gold-leafed page of Sapira's Art and Science of Bedside Diagnosis?" Another reviewer asked if there was any significance to this paper coming out of an academic centre in Alberta, which of course is irrelevant but does provide the opportunity to remind future citing authors that all the named rules in this paper are spelled "K-L-I-N-E," not "K-L-E-I-N."

There has been a movement among medical educators to abolish the "named" signs and diseases of medicine since they do not add clarity to the actual article. ${ }^{4}$ However, no suitable generic name has yet been suggested to replace "the organ of Zuckerkandl" (although I understand that this task is keeping a lot of medical policy-makers busy), so I'm not too concerned about losing my own named contributions. Finally, it should be remembered that not every reference cited in a discussion paragraph needs to be relevant to the issue at hand, ${ }^{5}$ but a long list of references assures the reader that the conclusions of the paper carry weighty clinical significance.

Gregory Kline is Clinicial Assistant Professor, Division of Endocrinology, at the University of Calgary, Calgary, Alta.

\section{References}

1. Kline GA. How to sound superior during a medical discussion. [In press, as far as anyone can prove.]

2. Kline GA. How to write a textbook that stays on the library shelf for a century. [Submitted for publication in some journal.]

3. Kline GA. Evidence-based philosophy: my way or the highway. [Presented in abstract form at a conference held in a tropical locale.]

4. Some medical educator (can't recall his name), personal communication.

5. Kline GA, Corenblum B. Giant prolactinoma causing isolated twelfth cranial nerve palsy: case report and review of extrasellar invasion by pituitary macroadenomas. Endocrinologist 2001;11(4):331-4. 